\title{
Author Correction: AgRP neurons control compulsive exercise and survival in an activity-based anorexia model
}

Maria Consolata Miletta (1), Onur Iyilikci, Marya Shanabrough (1), Matija Šestan-Peša (i), Allison Cammisa,

Caroline J. Zeiss, Marcelo O. Dietrich and Tamas L. Horvath (D)

Correction to: Nature Metabolism https://doi.org/10.1038/s42255-020-00300-8, published online 26 October 2020.

In the version of this article initially published, grant NKFI-126998 from the Hungarian National Research, Development and Innovation Office to author Tamas L. Horvath was not included in the Acknowledgements. The error has been corrected in the HTML and PDF versions of the article.

Published online: 25 January 2021

https://doi.org/10.1038/s42255-021-00351-5

๑ The Author(s), under exclusive licence to Springer Nature Limited 2021 